\title{
The possibility to perform surgery in late posttraumatic gastrothorax only on history and clinical exam
}

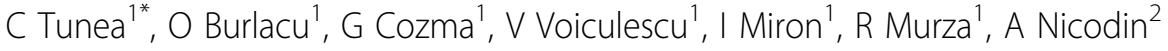 \\ From 23rd World Congress of the World Society of Cardio-Thoracic Surgeons \\ Split, Croatia. 12-15 September 2013
}

\section{Background}

Due to possible severe complications, posttraumatic gastrothorax must be surgically corrected as soon as the diagnosis is reached. We tried to demonstrate that history and clinical exam can lead to the right diagnosis and consequently to the surgical repair.

\section{Method}

We analyzed all cases with viscerothorax (8) admitted in 2002 - 2012. Four were gastrothorax. All the cases were clinically examined and at least one chest X-ray was taken with 4 of them having a CT.

\section{Results}

The diagnosis based on history (4 minimal stab wounds, 3 politrauma, and 1 difficult nephrectomy) and clinical exam matched the diagnosis. In one case (difficult nephrectomy two years before) the radiologic interpretation led to a wrong diagnosis of tension pneumothorax and a chest tube was inserted with consecutive gastric perforation and leakage of gastric content. Promptly recognized, thoracotomy was performed like in all the other cases.

\section{Conclusions}

It is difficult to diagnose a late gastrothorax when the traumatic event happened years ago and you base your diagnosis more on the radiological studies than on history and clinical exam. A careful history focusing on possible past traumas and a thorough clinical exam can give you the correct diagnosis.

\footnotetext{
* Correspondence: calin.tunea@gmail.com

'Department of Thoracic Surgery, Emergency Municipal Hospital Timisoara, Romania

Full list of author information is available at the end of the article
}

\section{Authors' details}

${ }^{1}$ Department of Thoracic Surgery, Emergency Municipal Hospital Timisoara, Romania. ${ }^{2}$ University of Medicine, Timisoara, Romania.

Published: 11 September 2013

doi:10.1186/1749-8090-8-S1-P43

Cite this article as: Tunea et al:: The possibility to perform surgery in late posttraumatic gastrothorax only on history and clinical exam. Journal of Cardiothoracic Surgery 2013 8(Suppl 1):P43.
Submit your next manuscript to BioMed Central and take full advantage of:

- Convenient online submission

- Thorough peer review

- No space constraints or color figure charges

- Immediate publication on acceptance

- Inclusion in PubMed, CAS, Scopus and Google Scholar

- Research which is freely available for redistribution
C Biomed Central

\section{Biomed Central}

